\title{
A NATUREZA JURÍDICA DOS OFENDÍCULOS E A RESPONSABILIDADE PENAL NOS CASOS DE LESÃO E PERIGO DE LESÃO A TERCEIROS
}

THE LEGAL NATURE OF OFFENDICES AND CRIMINAL RESPONSIBILITY IN THE CASES OF INJURY AND DANGER OF INJURY TO

THIRD PARTIES

\section{JUCEMAR DA SILVA MORAIS ${ }^{1}$ DANUZA ALVES DE ANDRADE BAVARESCO ${ }^{2}$ MARIA CAROLINA SILVA HELENO ${ }^{3}$}

ISSUE DOI: $10.21207 / 1983.4225 .524$

\section{RESUMO}

Este artigo teve como objetivo fazer uma análise da natureza dos ofendículos buscando o entendimento na doutrina penal acerca dos efeitos sobre a responsabilidade dos agentes envolvidos no tocante à lesão de terceiros inocentes, visto que o tratamento dado à questão dos ofendículos define a maneira como a problemática é tratada pelo Poder Judiciário e pela socie-

\footnotetext{
${ }^{1}$ Doutorando em Acesso à Justiça nas Constituições na Faculdade Autônoma de Direito Fadisp/SP. Mestre em Direito pela Unesp, campus de Franca/SP. Professor de Filosofia do Direito, Direitos Humanos e Direito Constitucional na Libertas Faculdades Integradas de São Sebastião do Paraíso/MG e Fafram - Faculdade Doutor Francisco Maeda de Ituverava/SP. Professor convidado na Faculdade de Direito de Franca/SP. Advogado.

${ }^{2}$ Graduanda do $4 .^{\circ}$ período do curso de Direito da Faculdade Doutor Francisco Maeda (Fafram) de Ituverava/SP.

${ }^{3}$ Graduanda do $4 .^{\circ}$ período do curso de Direito da Faculdade Doutor Francisco Maeda (Fafram) de Ituverava/SP.
} 
dade, refletindo na garantia do direito de defesa da propriedade no Brasil e outros bens jurídicos relevantes. O estudo não teve pretensão de esgotar o assunto, mas tão somente contribuir para a discussão acerca do direito de autodefesa e da responsabilidade dos proprietários no exercício regular do direito ou em legítima defesa. O método adotado para análise do objeto deste trabalho foi o dialético, tendo como fundamento teórico a doutrina penal e artigos acadêmicos relacionados. Foram pesquisados também artigos jurídicos e legislação correspondente.

Palavras-chaves: Ofendículos. Direito Penal. Legítima defesa. Exercício regular de direito. Proporcionalidade e excesso.

\section{ABSTRACT}

This essay aims to analyze the nature about offendiculas seeking to understand how the criminal doctrine defines the effects on the liability of stakeholders regarding the injury to innocent, as the understanding given to the issue of offendiculas defines the way the problem is treated by justice and society, and future effects on the guarantee of the property rights of defense and other relevant legal interests. The study did not intend to exhaust the subject, but only contributes to the discussion about the right to self-defense and the responsibility of the owners in the regular duty or in self-defense exercise. The method used to analyze the object in this work was dialectical, with the theoretical basis on criminal doctrine and related scholarly articles. They were also surveyed legal articles and related legislation.

Keywords: Offendiculas. Criminal law. Self-defense. Regular exercise of law. Proportionality and Excess.

\section{INTRODUÇÃO}

No dia 18 de fevereiro de 2008, uma tragédia abalou uma humilde família, na cidade de Cabo de Santo Agostinho/PE. Ao chegar em casa, uma jovem de 20 anos, desconhecendo uma armadilha que havia sido montada por seu pai para afugentar e atingir assaltantes que, em ocasiões anteriores, já haviam arrombado sua residência, acabou por vir a 
falecer em razão de uma forte descarga elétrica que recebeu ao cruzar com uma instalação elétrica montada por ele. ${ }^{4}$

Em outra ocasião, no dia 19 de abril do ano em curso, um homem foi encontrado morto, na cidade de Presidente Médici/RO, vítima de disparo de uma arma de fogo que, tal como no caso anterior, era parte de um aparato caseiro montado por um sitiante que já se dizia cansado de ser assaltado em uma série de furtos anteriormente praticados no local. A armadilha fora montada dentro da residência do sitiante que disparou assim que a porta foi aberta pela vítima, causando sua morte instantaneamente. $^{5}$

Os outros dois casos que se seguem, embora semelhantes, são ainda mais revoltantes. Em Pedra Branca do Amapari, cidade que se situa a 183 quilômetros de Macapá, uma menina de 10 anos morreu após ser atingida no tórax pelo disparo de uma arma de fogo caseira que foi colocada como armadilha para se evitarem furtos e invasão. A criança havia entrado no terreno do agressor, onde o aparato fora instalado, para procurar seu coelho de estimação, ocasião em que foi atingida pelo disparo. Finalmente, uma outra situação, não muito distinta desta última, porém ainda mais elaborada, vitimou um menino de apenas dois anos de idade, na capital Cuiabá, no Mato Grosso. No caso, a vítima morreu envenenada após ingerir um achocolatado que havia sido previamente preparado para servir como "isca" para um criminoso que, em ocasiões anteriores, já havia furtado alimentos na residência do agressor, um idoso que se dizia revoltado com a série de assaltos praticados na vizinhança. Sabedor disso, sua artimanha foi a de injetar com uma seringa o veneno na caixinha do achocolatado que, não tendo sido ingerido pelo assaltante, acabou sendo repassado para uma vizinha que, então, deu a bebida para seu filho ${ }^{67}$.

\footnotetext{
${ }^{4}$ G1 GLOBO. Jovem morre eletrocutada em armadilha para pegar ladrões. Disponível em <http://g1.globo.com/noticias/brasil/0,,mul305587-5598,00-jovem+morre+eletrocu tada+em+armadilha+para+pegar+ladroes.html >. Acesso em 18 jan. 2016.

${ }^{5}$ G1 GLOBO. Homem achado morto em sítio de RO foi baleado em armadilha artesanal. Disponível em: <http://g1.globo.com/ro/rondonia/noticia/2016/04/homem-achadomorto-em-sitio-de-ro-foi-baleado-em-armadilha-artesanal.html>. Acesso em 18 jan. 2016. ${ }^{6}$ G1 GLOBO. No AP, criança morre após entrar em quintal e ser baleada por armadilha. Disponível em: <http://g1.globo.com/ap/amapa/noticia/2016/06/no-ap-crianca-mo rre-apos-entrar-em-quintal-e-ser-baleada-por-armadilha.html>. Acesso em 18 jan. 2016.

7 O TEMPO. Achocolatado envenenado que matou menino era 'isca' para ladrão", disponível em: http://www.otempo.com.br/capa/brasil/achocolatado-envenenado-quematou-menino-era-isca-para-ladr\%C3\%A3o-1.1364382. Acesso em 18 jan. 2016.
} 
$\mathrm{O}$ que todos esses casos possuem em comum? O que explica sua ocorrência e quais as consequências jurídico-penais que eles geram e de que modo podem servir como paradigma para a reflexão dos institutos jurídicos que com eles se relacionam? Além de tudo isso, o que tais casos podem nos dizer sobre o estado atual do Direito Penal e do papel que o Estado exerce como o único detentor do monopólio do jus puniendi, em face da crescente sensação de impunidade e do resultado das estatísticas relativas ao crescente número de crimes a cada ano que passa ${ }^{8}$ ?

As manifestações individuais ou coletivas de violência, como acontece com os não raros casos de linchamento público, por exemplo, que, por sua vez, tem por finalidade a vingança de um (suposto) crime, via de regra, tendem a acontecer em locais em que o Estado está ausente ou omisso. Também acontecem nos lugares em que, quando presente, apresenta-se de forma precária ou ineficaz ou permite que a sociedade perceba essa ineficácia ou incapacidade de resolver seus problemas, sentindo-se desprotegida e desamparada. Ao se sentir dessa forma, deixa-se dominar pela revolta e, mais, pelo medo, sentimento que se torna ainda mais permanente quando acompanhado da sensação de impunidade e do desejo de buscarem resolver as coisas à sua maneira.

Fato é que, em rápida pesquisa feita via Google, é fácil de se notar como esses casos tem se tornado, infelizmente, corriqueiros e servido como uma clara demonstração de que esses tipos de crimes, representando a disposição que as pessoas têm para a prática de violência e a malfadada "justiça com as próprias mãos", como forma de se sentirem mais seguras, apenas se prestam a atestar a falência das instituições públicas que haveriam de se responsabilizar pela solução desses tipos de conflitos. Além disso, essas ocorrências têm se tornado cada vez mais comuns em cenários em que os direitos humanos e a defesa da vida, como valores fundamentais, têm sido esquecidos ou pouco debatidos, como ocorre no Brasil, especialmente nas regiões mais afastadas. E, por essa razão, como dito, ao dar vazão ao medo e buscando uma suposta segurança que não encontra nas instituições públicas, uma grande parcela da sociedade se dispõe a agir de forma violenta e, muitas vezes, desproporcional (porque motivada pela emoção e não pela razão) de modo que o resultado de suas

\footnotetext{
${ }^{8}$ INSTITUTO AVANTE BRASIL. Um estudo sobre a criminalidade feito pelo Instituto Avante Brasil, com dados relativos ao ano de 2013. Disponível em <http://d2kefwu52 uvymq.cloudfront.net/uploads/2015/06/Criminalidade-no-Brasil-2013.pdf>. Acesso em 10 jan. 2016.
} 
ações, muitas das vezes, acaba por ser ainda mais violento do que a causa que tenha provocado essa reação.

Considerando-se os casos que foram acima narrados e diante desse contexto apresentado, o presente artigo constitui um estudo crítico acerca dessa necessidade cada vez maior dos cidadãos brasileiros de se revestirem destas formas extremas de solução de conflitos, notadamente quando se veem na obrigação de buscar a defesa de bens jurídicos relevantes, tais como a propriedade, a vida e sua integridade física.

Conforme já foi dito, ao Estado cabe exercer o monopólio da força legítima em relação às questões de segurança pública. No entanto, a legislação brasileira reconhece que, nas situações em que o Estado não se faz presente, o indivíduo possui legitimidade para defender-se de quaisquer ameaças que possam incidir sobre sua propriedade, sobre si mesmo ou ainda terceiros, constituindo estas ações, quando observados os estritos requisitos legais previstos, as chamadas causas de justificação ou, simplesmente, excludentes de ilicitude.

Serão essas, portanto, em linhas gerais, as questões que servirão como aspectos a serem enfrentados e discutidos no presente artigo.

Sendo assim, para análise desse objeto, optou-se pela adoção do método dialético, contemplando as correntes da doutrina penal que apresentam interpretações divergentes sobre as questões que serão aqui tratadas. O referencial teórico que serviu de fundamento para análise do objeto de estudo apresenta obras doutrinárias no campo do Direito Penal e artigos científicos relacionados ao tema.

Nessa senda, considerando-se que nas situações que serão apresentadas será possível identificar-se o que a doutrina chama de colisão de princípios, será imprescindível em nossa análise o recurso, como meio de conciliação, do princípio da proporcionalidade, que tem como objetivo máximo preservar a dignidade humana e possibilitar parâmetros para a solução de conflitos entre bens jurídicos de valor constitucional, sempre com a ressalva de que nenhum direito ou garantia goza de valor supremo e absoluto, sendo sempre necessária a busca por harmonização do sistema.

Com isso, inicialmente, o estudo se ocupará de uma breve introdução sobre o direito de propriedade e o direito de defesa, levantando a problemática a ser discutida no decorrer da análise do objeto desta pesquisa. Em seguida, será feita uma breve explanação sobre a metodologia e os principais conceitos referentes às teorias que fundamentam a análise, 
apresentando conceitos gerais acerca dos institutos abordados e, por fim, uma análise das correntes doutrinárias que tratam da questão dos chamados ofendículos, confrontando os diversos posicionamentos a respeito, ressaltando-se os efeitos jurídicos com relação ao excesso ou abuso, bem como os casos em que existe lesão à terceiros, como nos casos que ilustram a abertura deste artigo.

\section{A DEFESA DA PROPRIEDADE E O CONTROVERSO USO DE OFENDÍCULOS}

A Constituição da República Federativa do Brasil, de 1988, dispõe que "[...] é garantido o direito de propriedade" (art. 5', XXII), sendo que o caput do mesmo dispositivo ainda determina que este direito é inviolável, assim como o direito à vida, à liberdade, à igualdade e à segurança, constituindo ainda cláusula pétrea (art. 60, $\S 4^{\circ}$, IV, da CRFB/1988), visto que integra o rol dos direitos de primeira dimensão entre os direitos fundamentais.

Dessa forma, nos casos em que o Estado não pode se fazer presente, o indivíduo possui legitimidade para defender sua propriedade, uma vez que "[...] a casa é asilo inviolável do indivíduo, ninguém nela podendo entrar sem consentimento do morador, salvo em caso de flagrante delito ou desastre, ou para prestar socorro, ou, durante o dia, por determinação judicial" (art. 5, XI, da CRFB/88).

Uma das formas de proteger não somente a propriedade, como também outros bens jurídicos, tais como a vida e a integridade física, é o uso de ofendículos, que nada mais são do que obstáculos que servem de impedimento para a entrada não autorizada em quaisquer propriedades, como, por exemplo, o uso de cercas elétricas, a colocação de cacos de vidro nos muros, a aquisição de cães para guarda e outros recursos. No entanto, para que sejam considerados legais, os ofendículos devem ser perceptíveis, notórios, dispostos de maneira visível de forma que o invasor, ao violar o domicílio, esteja assumindo o risco interposto pelos ofendículos. Nesse sentido, segundo Mirabete, os ofendículos ou offendicula

são aparelhos para a defesa da propriedade (arame farpado, cacos de vidro em muros, etc.) visíveis e a que estão equiparados os meios mecânicos ocultos 
(eletrificantes de fios, de maçanetas de portas, a instalação de armas prontas para disparar a entrada de intrusos, etc). ${ }^{9}$

Muitos autores, no entanto, fazem distinção dos ofendículos em relação às chamadas defesas mecânicas sendo que ambos seriam espécies do gênero defesas predispostas. A distinção estaria relacionada, basicamente, com o quesito visibilidade ${ }^{10}$. Neste contexto, para os autores que fazem essa distinção, há a necessidade de se buscar contemplar o caso concreto, visto que a guarda feita por cães treinados pode constituir ofendículo caso exista algum aviso externo, de modo que o invasor ao decidir por violar a propriedade esteja consciente dos riscos. Mas, caso não exista nenhuma placa de aviso sobre cães bravios no local, este configura defesa mecânica predisposta e, a depender de seus efeitos, também ato ilícito pelo excesso. Para Cezar Roberto Bitencourt

os ofendículos seriam percebidos com facilidade pelo agressor, como fragmentos de vidros sobre o muro, pontas de lança, grades, fossos etc., que representam uma resistência normal, natural, prevenindo quem tentar violar o direito protegido. As defesas mecânicas predispostas, por sua vez, encontrar-se-iam ocultas, ignoradas pelo suposto agressor, como, por exemplo, armas automáticas predispostas, cercas eletrificadas ou qualquer tipo de armadilha pronta para disparar no momento da agressão ${ }^{11}$.

A questão que vem a surgir, diante dessa distinção, diz respeito ao excesso (doloso ou culposo) que o uso de tais mecanismos poderá representar, notadamente no que se refere às defesas mecânicas serem um recurso oculto e que, por essa razão, não permitem ao agressor ponderar acerca dos riscos a que estará sendo submetido. Outrossim, mesmo os ofendículos, que possuem a prerrogativa de visibilidade, podem ser con-

\footnotetext{
${ }^{9}$ MIRABETE, Julio Fabbrini; FABBRINI, Renato N. Manual de Direito Penal: Parte Geral. v. 1.24 ed. São Paulo: Saraiva, 2007, p. 109.

${ }^{10}$ BITENCOURT, Cezar Roberto. Tratado de Direito Penal. Parte Geral. 22. ${ }^{a}$ Edição. São Paulo: Saraiva, 2016, p. 434.

${ }^{11}$ Ibidem.
} 
siderados excessivos e, com isso, incorrerá o agente em algum tipo de responsabilização no âmbito penal. Há que se considerar, nesse sentido, que a instalação de ofendículos para a defesa da propriedade deve obedecer a determinadas condições de moderação, visto que a doutrina e a jurisprudência brasileira entendem que a "reação" ao invasor deve ser proporcional ao dano ou ameaça.

Porém, considerando que os ofendículos são aparatos que funcionam de maneira independente, já que são programados para atuar na ausência do proprietário, de forma gradual e uniforme, quando artificiais, ou até de forma imprevisível, como no caso dos cães de guarda, como medir esse grau de moderação, sendo que o invasor supostamente viola 0 domicílio assumindo os riscos decorrentes desses artefatos?

Em tais casos, como faz refletir Francisco de Assis Toledo, discute-se a respeito da melhor localização dos ofendículos, lembrando que Nélson Hungria e Magalhães Noronha estudam tais dispositivos no capítulo da legítima defesa enquanto Bettiol e Aníbal Bruno preferem situálos no exercício regular de um direito ${ }^{12}$. Por outro lado, a jurisprudência tem tratado, em regra, os casos envolvendo ofendículos no âmbito da legítima defesa preordenada. Mas, seria esta definição a mais adequada? O termo "preordenado" por si só, não pode ser considerado elemento que descaracteriza o que está definido como legítima defesa no código penal?

É o que se passará analisar a seguir.

\section{$1.1 \quad$ ILICITUDE}

Uma ação ou omissão, para que seja considerada um injusto penal, deve constituir fato típico e ilícito, como se sabe ${ }^{13}$. Dessa forma, não basta a existência de uma contradição entre a conduta e o ordenamento jurídico, faz-se necessário, ainda, que esta ação ou omissão seja contrária

\footnotetext{
12 TOLEDO, Francisco. Princípios Básicos de Direito Penal. $4^{\mathrm{a}}$ Edição. São Paulo: Saraiva, 1991, p. 206.

${ }^{13}$ Para Francisco de Assis Toledo, o "injusto é a própria conduta valorada como antijurídica. O injusto tem assim um caráter substantivo que é posto em destaque nesta definição singela, mas bastante expressiva, de Schmindhäuser: injusto é algo que não nos é permitido fazer. Note-se que o conceito de injusto engloba toda e qualquer ação típica e antijurídica, mesmo que não seja culpável". Cf. TOLEDO, Princípios Básicos de Direito Penal.

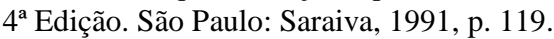


ao direito como um todo. Consoante esta propositura, pode-se afirmar que a antijuridicidade ou ilicitude que, ao lado da tipicidade, compõe o tipo de injusto, consiste na valoração que será realizada pelo juiz quanto à natureza lesiva de um comportamento humano, consistente em uma ação ou omissão, que possa resultar em algum tipo de lesão ou risco de lesão a um interesse relevante protegido pelo Direito Penal. ${ }^{14}$

Nesses termos, o juiz, mediante um processo de valoração, verifica se há indício de ilicitude, para que o fato típico seja considerado ilícito ou não. Para tanto, há que se considerar as excludentes que lhe são relacionadas, a saber: legítima defesa, estado de necessidade, exercício regular do direito e estrito cumprimento do dever legal.

A legislação brasileira, a partir das regras previstas no Código Penal, define o instituto da legítima defesa como "[...] quem, usando moderadamente dos meios necessários, repele injusta agressão, atual ou iminente, a direito seu ou de outrem" (art. 25, do Código Penal). Dessa forma, é possível afirmar que, para que seja considerada a legítima defesa do agente, é preciso que este esteja sob injusta agressão, perigo atual ou iminente, bem como a ação deve ocorrer a direito próprio ou em defesa de terceiro. Outrossim, os meios utilizados pelo agente devem ser proporcionais ao dano ou ameaça, com uso moderado dos meios necessários.

O exercício regular do direito envolve condutas que, apesar de tipificadas em lei, não são ilícitas devido aos limites formais e materiais em que ocorrem, sendo decorrentes do próprio direito. No entanto, uma vez rompidos esses limites, configura-se o abuso, tendo como consequência a exclusão da causa de justificação que eliminaria a hipótese de ilicitude do ato. Dessa forma, "O exercício regular de um direito jamais poderá ser antijurídico. Deve-se ter presente, no entanto, que a ninguém é

\footnotetext{
${ }^{14}$ Assis Toledo debruça-se sobre a controvérsia na adoção das expressões antijuridicidade e ilicitude, optando por esta última, como o fez o legislador na Reforma Penal de 1984. Nesse sentido, ele considera que a "reforma penal brasileira (Lei n. ${ }^{\circ}$ 7.209/84), ao dar nova redação à Parte Geral do Código Penal, adotou, portanto, o termo correto ilicitude (...). Andou bem, portanto, o legislador de 1984, no particular, ao retomar a melhor tradição portuguesa, contribuindo para afastar, segundo se espera, daqui por diante, o equívoco linguístico que parece ter sido fruto de importação de uma tradução pouco precisa da palavra composta alemã Rechtswidrigkeit, que significa, literalmente, contrariedade ao direito (não ao jurídico). Com efeito, ilícito é o fato que contraria o ordenamento jurídico". Por essa razão, adotaremos neste artigo, a partir daqui, o termo ilicitude. Cf., nesse sentido, TOLEDO, Princípios Básicos de Direito Penal. $4^{a}$ Edição. São Paulo: Saraiva, 1991, p. 160.
} 
permitido fazer justiça com as próprias mãos, salvo quando a lei o permite"15.

Diferente do estado de necessidade, em que subsiste a inexigibilidade de conduta diversa do agente, nas circunstâncias em que ocorre o exercício regular do direito, a ilicitude é afastada porque a ação obedece a todos os requisitos jurídicos, como, por exemplo, nas competições desportivas de artes marciais, em que a agressão física não é antijurídica pela própria natureza da atividade esportiva. No entanto, ocorrendo abuso desse direito, como, por exemplo, no caso do atleta que, desobedecendo as regras do esporte, golpeia o adversário diversas vezes no joelho com a finalidade de provocar lesão permanente, este deverá responder por dolo ou culpa, conforme a sua conduta.

Considerando, portanto, estas as espécies de causas que excluem a ilicitude de um fato e, com isso, retomando-se a discussão em torno dos chamados ofendículos, há de se analisar, de forma mais aprofundada e específica, sua natureza jurídica e, assim, verificar qual o enquadramento, sobretudo quando vitimarem, como em alguns dos casos concretos que ilustram as primeiras linhas desse artigo, terceiros inocentes e que não provocaram, por sua livre vontade, uma agressão injusta capaz de justificar o uso desses mecanismos de defesa.

\section{OFENDÍCULOS: LEGÍTIMA DEFESA OU EXERCÍCIO DE DIREITO?}

A questão, conforme já aventamos anteriormente, não goza de pacificação doutrinária.

Na jurisprudência, no entanto, existe uma tendência de se considerar o uso dos ofendículos para defesa da propriedade como legítima defesa preordenada, sendo este o entendimento adaptado na grande maioria dos casos em que foi necessário o acionamento dos sistemas judiciais, tendo em vista que estes artefatos, embora sejam preordenados (diante de uma instalação prévia e que antecede à prática de uma agressão ao bem jurídico sob proteção, e daí porque sua denominação), eles atuam no mo-

15 BITENCOURT, Cezar Roberto. Tratado de Direito Penal. Parte Geral. 22. ${ }^{\text {a }}$ Edição. São Paulo: Saraiva, 2016, p. 367. 
mento da agressão. Por esse motivo, constituiriam um caso de legítima defesa.

No entanto, primeiramente, há que se questionar se, nesses casos concretos, tem-se a presença dos requisitos necessários para caracterização da legítima defesa. Assim, de acordo com Gracieli Firmino da Silva,

A simples instalação de um obstáculo de proteção de um bem jurídico não gera consequência no mundo fático. Com efeito, no instante em que o bem protegido é ameaçado, efetivamente o ofendículo entra em funcionamento. Neste instante surge, para o cenário jurídico, uma agressão injusta passível de uma defesa lícita. Esse é o argumento dos defensores da ideia que o uso de ofendículos caracteriza legítima defesa preordenada ${ }^{16}$.

O critério utilizado para contrapor a tese que vem prevalecendo no âmbito dos tribunais está fundamentado no elemento da atualidade. Perigo atual ou iminente não se confunde com ameaça. $\mathrm{O}$ fundamento para o uso de ofendículos é justamente o temor ou o risco de se ter um bem jurídico lesado, fazendo com que o indivíduo rogue para si o direito de defender-se, utilizando-se dos meios necessários para tal. Se assim é, ou seja, se o critério passa a ser uma ameaça ou perigo ao bem jurídico protegido e não uma lesão atual ou iminente, o melhor entendimento para enquadrar os ofendículos, considerando-se o momento anterior ao seu acionamento, seria, portanto, o exercício regular do direito de defesa. Consoante estes argumentos, afirma Aníbal Bruno:

Não nos parece que a hipótese possa ser resolvida como a legítima defesa... embora o aparelho só se destine a funcionar no momento do ataque, a verdadeira ação do sujeito é anterior: no momento da agressão, quando cabia a reação individual, ele, com o seu gesto e a sua vontade de defesa, está ausente.

\footnotetext{
${ }^{16}$ SILVA, Gracieli Firmino da. Ofendículos e suas implicações no Direito Penal brasileiro. Dissertação de Mestrado. São Paulo: Pontifícia Universidade Católica - PUC, 2006, p. 82. Disponível em: <http://www.sapientia.pucsp.br/tde_busca/arquivo.php?codArq uivo=4210>. Acesso em: 23 nov. 2015.
} 
Além disso, a atuação do aparelho é automática e uniforme, não pode ser graduada segundo a realidade e a importância do ataque... Por tudo isso, esse proceder fica distante dos termos precisos da legítima defesa, que supõe sempre um sujeito atuando, com o seu gesto e o seu ânimo de defenderse, no momento mesmo e com a medida justa e oportuna contra a agressão atual ou iminente". ${ }^{17}$

Todavia, esse entendimento, conforme já se registrou, não é unânime na doutrina.

José Cirilo Vargas contrapõe estes argumentos afirmando que, apesar de constituírem defesas predispostas, estas somente devem atuar no momento da agressão, implicando, portanto, legítima defesa preordenada. De acordo com o autor, "no caso de defesas predispostas, costumase questionar a atualidade ou iminência da agressão. Acontece que o offendiculum só vai funcionar se efetivamente houver agressão. Não colhe o argumento de agressão incerta e futura" 18 .

Segundo Nelson Hungria, citado por Assis Toledo, os ofendículos são admissíveis mesmo com o risco de que, ao invés do ladrão, venha a ser vítima do aparato uma pessoa inocente. Nesse caso, para o autor, tratar-se-ia de uma legitima defesa putativa. ${ }^{19}$

Cezar Roberto Bitencourt adota entendimento moderado com relação à natureza dos ofendículos, compreendendo que, no momento da instalação dos aparelhos, o indivíduo está em pleno exercício regular de direito, mas no instante em que ocorre a agressão e estes entram em funcionamento, essa reação passa a constituir legítima defesa preordenada, implicando em uma teoria híbrida ${ }^{20}$.

Tanto o argumento da legítima defesa preordenada, quanto o exercício regular de direito constituem exclusão de ilicitude. No entanto,

${ }^{17}$ BRUNO, Aníbal. Direito penal I - parte geral. Rio de Janeiro: Forense, 1966. t. 2, p. 91.

18 VARGAS, José Cirilo. Instituições de direito penal. Parte geral. Belo Horizonte: Del Rey, 1997, T. I, p. 337.

19 TOLEDO, Francisco. Princípios Básicos de Direito Penal. 4 ${ }^{\text {a }}$ Edição. São Paulo: Saraiva, 1991, p. 206.

${ }^{20}$ BITENCOURT, Cezar Roberto. Tratado de Direito Penal. Parte Geral. 22. ${ }^{\text {a }}$ Edição. São Paulo: Saraiva, 2016, p. 434-435. 
diferem nos efeitos quando há excessos no uso dos ofendículos, inclusive quando prejudica terceiros. No primeiro caso, configura-se o uso imoderado dos meios necessários para defender-se, no segundo, existe abuso de direito.

Por essa razão, diante dessa hipótese de excesso ou abuso na utilização dos meios para defesa, passaremos a tratar desse aspecto em separado.

\subsection{MODERAÇÃO E LESÃO A TERCEIROS}

O excesso cometido com o uso imoderado de ofendículos pode incorrer, dependendo das circunstâncias, em dolo ou culpa, cabendo a responsabilidade penal sobre o eventual descuido dos aparelhos de defesa. Não seria essa a hipótese dos casos acima analisados? Nesse sentido, diante da evidente necessidade de responsabilização do agressor, necessário analisar os aspectos jurídicos relativos a tais casos. Adverte Bitencourt que

O excesso será doloso quando o agente, deliberadamente, aproveitar-se da situação excepcional que lhe permite agir, para impor sacrifício maior do que o estritamente necessário à salvaguarda do seu direito ameaçado ou lesado. Configurado o excesso doloso, responderá o agente dolosamente pelo fato praticado, beneficiando-se somente pela atenuante do art. 65, II, $c$, ou com a minorante do art. $121, \S 1^{\circ}$, quando for o caso. Será culposo o excesso quando, por descuido ou imprevisão, o agente ultrapassa os limites da ação permitida, podendo decorrer de erro de tipo inescusável. O excesso culposo só pode decorrer de erro havendo uma avaliação equivocada do agente sobre a perigosidade de sua conduta quando, nas circunstâncias, lhe era possível avalia-la adequadamente. Enfim, o excesso punível, que pode configurar-se em qualquer das excludentes legais, seja a título de dolo, seja a título de culpa, decorre do exercício imoderado ou descuidado de determinado direito ou dever, que acaba produzindo resultado 
mais grave do que o razoavelmente suportável e, por isso mesmo, nas circunstâncias, não permitido ${ }^{21}$

O excesso pode se configurar, por exemplo, contra terceiros inocentes quando o cão bravio por descuido ou negligência escapa aos limites da propriedade, atacando transeuntes na rua. Não são raros os casos de ataques de cães por negligência dos proprietários. Nelson Hungria, repita-se o que já registramos anteriormente, advoga a tese de que a lesão contra terceiros inocentes constitui legítima defesa putativa, visto que o agente proprietário do ofendículo não apresentava manifesta vontade de lesionar terceiros, mas tão somente preservar o bem jurídico, tornando a conduta do agente, por conseguinte, lícita.

Se considerada a natureza dos ofendículos como exercício regular do direito e não como legítima defesa, a lesão a terceiros pode configurar, a depender da forma como o sujeito instalou o aparato de defesa, abuso de direito, uma vez que o exercício do direito de defesa da sua propriedade feriu bem jurídico de terceiros, extrapolando os limites impostos pelo direito, cabendo-lhe a responsabilidade sobre o fato. No entanto, fazse necessário considerar que;

Tudo se resume na apreciação do fato, que, como nos outros casos de legítima defesa, pode comportar excesso. Quem eletrifica a porta de sua casa, que dá para a calçada da rua, age com culpa manifesta, senão com dolo, pois qualquer transeunte pode tocar ou encostar nela. Entretanto, quem assim fizer com a porta de uma casa rodeada de jardins e quintais e cercada por altos gradis e muros, de modo que é necessária a escalada, à noite, para tocar naquela, não age com culpa strictu sensu ${ }^{22}$.

Dessa forma, o direito de autodefesa ou de defesa da propriedade não reina absoluto, visto que, se considerada a condição de legítima

${ }^{21}$ BITENCOURT, Cezar Roberto. Tratado de Direito Penal. Parte Geral. 22. ${ }^{\text {a }}$ Edição. São Paulo: Saraiva, 2016, p. 369.

${ }^{22}$ SOUZA, Gilson Sidney Amancio. O tratamento das ofendículas na doutrina brasileira. Disponível em: <http://www.buscalegis.ufsc.br/revistas/files/anexos/11505-115051-PB.htm>. Acesso em: 24 nov. 2015. 
defesa, é preciso observar o requisito da moderação, por conseguinte, para que exista a excludente de ilicitude, o agente deve reagir de maneira proporcional à agressão, caso contrário, configurando o excesso ou descuido na instalação do aparato de defesa, descaracteriza-se a legítima defesa putativa com relação a terceiros. Se considerado o exercício regular do direito, tem-se que tal prerrogativa não deve exceder o direito de outrem, prejudicando bem jurídico alheio. Em quaisquer das situações cabe análise das circunstâncias no caso concreto.

\section{CONSIDERAÇÕES FINAIS.}

O presente artigo teve como objetivo tecer uma reflexão acerca da natureza dos ofendículos a partir das correntes doutrinárias no Direito Penal, de maneira a contemplar os efeitos jurídicos que cada visão implica para a sociedade.

A corrente que entende que a natureza dos ofendículos constitui legítima defesa preordenada alega que, apesar da anterioridade da instalação do aparato, este somente entra em uso no momento da agressão, o que implica legítima defesa tendo em vista que o aparelho somente funciona mediante injusta agressão atual ou iminente.

Já os autores que advogam a tese de que os ofendículos constituem exercício regular do direito de defesa da propriedade argumentam que esse enquadramento se deve ao fato de que não estão presentes os requisitos da legítima defesa no momento da reação ao injusto, inclusive considerando que não há como estabelecer-se a medida da moderação, uma vez que os aparatos de defesa funcionam de maneira uniforme e independente da presença do proprietário, não computando o animus defendendi necessário para a subsunção da legítima defesa.

As implicações divergem de acordo com a teoria adotada.

No Brasil, vem predominando, na jurisprudência, a corrente doutrinária da legítima defesa preordenada, o que, no caso de excesso ou lesão a terceiros, favorece o agente que se valeu dos mecanismos protetivos em excesso e, com isso, em tese, possibilita a aplicação de legítima defesa putativa.

Finalmente, se considerado o uso de ofendículos como uma forma de exercício regular do direito, tem-se que a responsabilidade que recai sobre o agente proprietário é maior, visto que o exercício do direito 
de autotutela da propriedade não pode resultar em prejuízo do bem jurídico de outrem, a depender de qual bem jurídico foi atingido no caso concreto. De todo modo, para aqueles que optarem por fazer uso dos ofendículos, a cautela há de ser sempre redobrada, sendo que o risco da utilização inadequada de tais dispositivos correrá por conta de quem os utilizar. Por essa razão, a moderação dos efeitos e a prudência em evitar medidas excessivas são de extrema importância, especialmente se forem analisados a partir dos requisitos de legítima defesa que, para ser reconhecida, haverá de tê-los todos devidamente reconhecidos.

\section{REFERÊNCIAS BIBLIOGRÁFICAS.}

BITENCOURT, Cezar Roberto. Tratado de Direito Penal. Parte Geral. 22. ${ }^{\text {a }}$ Edição. São Paulo: Saraiva, 2016.

BRUNO, Aníbal. Direito penal I - parte geral. Rio de Janeiro: Forense, 1966. t. 2.

G1 GLOBO. Homem achado morto em sítio de RO foi baleado em armadilha artesanal. Disponível em: <http://g1.globo.com/ro/rondonia/noticia/2016/04/homem-achadomorto-em-sitio-de-ro-foi-baleado-em-armadilha-artesanal.html>. Acesso em 18 jan. 2016.

. Jovem morre eletrocutada em armadilha para pegar ladrões. Disponível em <http://g1.globo.com/noticias/brasil/0,,mul305587$5598,00-$

jovem+morre+eletrocutada+em+armadilha+para+pegar+ladroes.ht ml>. Acesso em 18 jan. 2016.

. No AP, criança morre após entrar em quintal e ser baleada por armadilha.

Disponível em:

<http://g1.globo.com/ap/amapa/noticia/2016/06/no-ap-criancamorre-apos-entrar-em-quintal-e-ser-baleada-por-armadilha.html> . Acesso em 18 jan. 2016.

INSTITUTO AVANTE BRASIL. Um estudo sobre a criminalidade feito pelo Instituto Avante Brasil, com dados relativos ao ano de 2013. Disponível em <http://d2kefwu52uvymq.cloudfront.net/u ploads/2015/06/Criminalidade-no-Brasil-2013.pdf>. Acesso em 10 jan. 2016.

MIRABETE, Julio Fabbrini; FABBRINI, Renato N. Manual de Direito Penal: Parte Geral. v. 1. 24 ed. São Paulo: Saraiva, 2007. 
O TEMPO. Achocolatado envenenado que matou menino era 'isca' para ladrão", disponível em: http://www.otempo.com.br/capa/b rasil/achocolatado-envenenado-que-matou-menino-era-isca-paraladr\%C3\%A3o-1.1364382. Acesso em 18 jan. 2016.

SILVA, Gracieli Firmino da. Ofendículos e suas implicações no Direito Penal brasileiro. 2006. 158f. Tese (Mestrado em Direito Penal). Pontifícia Universidade Católica - PUC, SP. São Paulo, 2006. Disponível em: <http://www.sapientia.pucsp.br/tde_busca/arquivo. php?codArquivo=4210 >. Acesso em: 23 nov. 2015.

SOUZA, Gilson Sidney Amancio. O tratamento das ofendículas na doutrina brasileira. Out. 2001. Disponível em: < http://www.buscalegis.ufsc.br/revistas/files/anexos/11505-115051-PB.htm>. Acesso em: 24 nov. 2015.

TOLEDO, Francisco. Princípios Básicos de Direito Penal. $4^{\mathrm{a}}$ Edição. São Paulo: Saraiva, 1991.

VARGAS, José Cirilo. Instituições de direito penal. Parte geral. Belo Horizonte: Del Rey, 1997, T. I. 
